\title{
LITERATURA FANTÁSTICA ENTRE EL DIARIO CRÍTICA Y LA EDITORIAL SUDAMERICANA: POLÍTICAS EDITORIALES, MATERIALIDAD DE LOS TEXTOS Y MODOS DE ESCRITURA
}

\author{
María de los Ángeles Mascioto \\ Universidad Nacional de La Plata - CONICET \\ mariamascioto@gmail.com
}

\section{RESUMEN / ABSTRACT}

Este trabajo analiza los modos en que las transformaciones materiales y textuales que experimentaron una serie de textos al ser publicados y leídos en tres contextos de edición diferentes afectaron su significado (la Revista Multicolor de los Sábados, suplemento literario del diario Crítica, y dos distintas ediciones de la Antología de la Literatura Fantástica, compilada por Jorge Luis Borges, Adolfo Bioy Casares y Silvina Ocampo en 1940 y 1965). Sostenemos que una parte de la propuesta de renovación literaria que significó la Antología de la Literatura Fantástica habría sido ensayada en la década del treinta en el suplemento de Crítica. Las sucesivas reediciones habrían implicado una revisión tanto de la escritura de los textos como del lugar que se le otorgó al género fantástico y el modo en que este género se presentó a los lectores.

PALABRAS ClAVE: literatura fantástica, literatura argentina, traducción, publicaciones periódicas, políticas editoriales.

This paper analizes changes in material and textual form experimented by a group of texts published and read in three different edition contexts (Revista Multicolor de los Sábados, Critica's Cultural and Litterary Supplement, and two different editions of Antología de la Literatura Fantástica, compiled by Jorge Luis Borges, Adolfo Bioy Casares y Silvina Ocampo, 1940 \& 1965). At the same time, this work studies the way in which those changes affected the significance of the texts. We propose the hypothesis that a part or literary renovation promoted by Antología de la Literatura Fantástica has been tested in the thirties decade in the context of Critica's Litterary Supplement. The successive editions of those stories have involved a revission of both writing texts and the place that was given to fantasy and how this genre was presented to readers.

KEYWORDS: fantastic literature, argentinian literature, translation, periodicals, publishing policies. 
El martes 3 de noviembre de 1953, Adolfo Bioy Casares escribía en su diario: "Come en casa Borges. Buscamos en números viejos de Crítica (al hacerlo, advierto en él desagrado e incomodidad), cuentos de Santiago Dabove (malos) y de otros para la nueva antología fantástica" (Bioy Casares 92). El autor hace referencia, por un lado, a la configuración de una segunda edición de la Antología de la literatura fantástica ${ }^{1}$, que podemos asociar con aquella que se publicaría varios años más tarde, en 1965. Y, por otro, a la vigencia que aún tenían los cuentos que Dabove había publicado veinte años atrás en la Revista Multicolor de los Sábados ${ }^{2}$, suplemento literario y cultural del diario argentino Crítica que se distribuyó entre agosto de 1933 y octubre de 1934 bajo la dirección de Jorge Luis Borges y Ulyses Petit de Murat $^{3}$. En efecto, pese al desagrado que Bioy Casares encontraba en Borges al momento de releer el masivo y sensacionalista diario Crítica, la $R M S$ fue, en los años treinta, un primer espacio de promoción de varios relatos que poco tiempo después pasaron a conformar antologías de los géneros policial

\section{En adelante, $A L F$}

En adelante, $R M S$

Este suplemento de Crítica publicó 61 ejemplares, compuestos cada uno por ocho páginas de 58 por 45 centímetros, que se distribuyeron en forma gratuita con la compra del periódico, cuyo precio era de 0,10 centavos. La Revista Multicolor, que contó con la colaboración de escritores como Jorge Luis Borges, Juan L. Ortiz, Norah Lange, Raúl González Tuñón, Enrique Amorim, Carlos de la Púa, los hermanos Dabove, Victor J. Guillot, Manuel Peyrou, Carlos Moog, González Lanuza, Vicente Rossi, Juan Carlos Onetti, formó parte del proceso de expansión de la prensa periódica que, desde fines del siglo XIX, produjo numerosos cambios en el periodismo argentino, como la incorporación de nuevos formatos periodísticos y la construcción de nuevos estilos. Durante este período, el mercado (más que el sistema político) comenzó a regular la aparición de nuevos diarios, lo que permitió el reemplazo de una larga tradición de prensa partidaria por un periodismo de carácter más comercial. En ese marco, muchos escritores argentinos incorporaron en sus obras formas de la cultura de masas y ciertas formas de la cultura de masas absorbieron elementos de la alta cultura. El diario Critica, fundado en 1913 por Natalio Botana, fue una publicación sujeta en muchos sentidos a los modelos técnicos de la prensa amarilla norteamericana iniciada por Hearst y Pulitzer, lo que lo orientó claramente hacia el público masivo, al que buscó ofrecer literatura para el consumo popular (Saítta, Regueros de tinta). Si nos atenemos a los relatos literarios de la Revista Multicolor, es relevante no solo la temática sino el tipo de escritura de los textos publicados en ella y los vínculos que éstos establecieron con aquellos que aparecieron en el cuerpo del diario, en cuyas páginas se puede observar una redacción atractiva y agresiva de los titulares, historias de "interés humano", una importante presencia de ilustraciones que dejaban de ser pasivas acompañantes de las noticias para ser reconstrucciones gráficas de los acontecimientos (Rivera, El escritor). 
y fantástico, como Los mejores cuentos policiales (1943), y la ALF (1940). María Teresa Gramuglio señaló que ambos volúmenes antológicos formaron parte de un operativo llevado a cabo por Borges y Bioy Casares alrededor de la década de 1940 para crear las condiciones de recepción de sus propios textos (Gramuglio 288). Sin embargo, una vez creadas estas condiciones, ya en los años cincuenta, cabe preguntarse por qué ambos compiladores volvían una vez más a revisar las páginas del suplemento de Crítica. Una posible respuesta es que el contexto en el que se crearon las condiciones de recepción de estos textos no comenzó solo en Sur, sino más bien entre esta revista de Victoria Ocampo, en la que se divulgó un discurso crítico en torno al fantástico, y el suplemento especializado de un medio popular y masivo (la $R M S$ ), en el que se publicaron ficciones que participaban del género.

En la $R M S$ no solo se tradujeron, sino que se escribieron varios cuentos fantásticos y policiales. En sus páginas se publicaron nueve de los textos que luego aparecerían en la antología fantástica compilada por Borges, Ocampo y Bioy Casares ${ }^{4}$ : en la edición de 1940, los antologadores tomaron del suplemento de Crítica un cuento escrito por un autor argentino ("Ser polvo", de Santiago Dabove), una serie de relatos de escritores anglosajones (algunos de ellos muy promocionados por Borges en otros ámbitos, como May Sinclair y H. G. Wells), un texto español también incluido en otras colecciones de Borges ("El brujo postergado") ${ }^{5}$ y una pieza de teatro compuesta en un acto único de Eugene O’ Neill. En la segunda edición (1965), se volvió a mirar la $R M S$ para incluir, además de los cuentos anteriormente mencionados, uno de los relatos chinos publicados mucho tiempo antes en el suplemento. En este marco podemos preguntarnos por qué la editorial Sudamericana decidía lanzar una nueva edición de aquella antología fantástica que había salido en la década del cuarenta y cuáles fueron -de haber existido- los cambios que

4 Estos relatos son: "Ser polvo", de Santiago Dabove; "Los ganadores de mañana", de Holloway Horn; "El brujo postergado", de Don Juan Manuel; "Donde su fuego nunca se apaga", de May Sinclair; "Un teólogo en la muerte", de Manuel Swedenborg (que en el suplemento de Crítica se titula "El teólogo"); "Historia de dos que soñaron", de Gustavo Weil (en la Revista Multicolor: "Dos que soñaron”); "El caso del difunto Míster Elvesham”, de H. G. Wells; y el acto único "Donde está marcada la cruz", de Eugene O' Neill, que aparecieron en la primera edición de la $A L F$, y el cuento "La sentencia", que aparece en la segunda edición de la antología, en la $R M S$ formaba parte del artículo "Relatos Chinos".

Este relato formó parte también de la colección de Historia Universal de la Infamia, de Jorge Luis Borges (1935). 
experimentaron los textos que aparecieron primero en la $R M S$ y luego en las dos ediciones de la $A L F^{6}$.

Si como ha señalado Roger Chartier, "El pasaje de una forma editorial a otra ordena simultáneamente transformaciones del texto y la constitución de un nuevo público" (32) ${ }^{7}$, el objetivo de este trabajo es analizar el modo en que las transformaciones materiales y textuales que experimentaron estos nueve textos al ser publicados y leídos en tres contextos de edición diferentes afectaron su significado. Identificamos tres etapas en la promoción y escritura del fantástico: una primera de inicios, en la que estos nueve textos se difundieron por primera vez y de manera masiva en el suplemento

$6 \quad$ Pese a las reiteradas menciones de la $A L F$ en diversas historias y manuales de la literatura argentina, llama la atención el escaso estudio que recibieron los relatos publicados en ella. Del mismo modo, en los análisis sobre este libro colectivo nada se ha mencionado sobre la publicación previa de alguno de los textos que lo integraron en la $R M S$. Este aspecto ha sido escuetamente advertido por quienes estudiaron la presencia de Borges como director y escritor en el suplemento de Crítica (Cf. Jorge B. Rivera, "Los juegos"; Louis Annick, Jorge Luis Borges), aunque quedan por analizar de qué manera y con qué fines aparecieron esos textos allí y por qué se retomaron años después para ser publicados en formato libro. Si los estudios sobre esta antología se han enfocado principalmente en los motivos y las estrategias de selección del corpus literario (se han estudiado extensamente los intereses literarios de los compiladores -el rechazo de Borges contra el realismo y su afición por los géneros menores, la intencionalidad de los prólogos y reseñas que realizaron Borges y Bioy Casares en otros medios-, se han analizado también algunos aspectos significativos del paratexto, como el prólogo de Bioy Casares a la primera edición y la presencia de textos apócrifos en las notas introductorias de los relatos, las diferencias en el orden de los cuentos entre la primera y la segunda edición), la crítica aún no se ha detenido en un estudio particular de los textos que ella contiene (Balderston; Louis, "Definiendo"; Zavala Medina). De esta manera, la antología de Borges, Ocampo y Bioy Casares ha sido considerada como el espacio de promoción de un nuevo modo del fantástico sin tener en cuenta los cambios que se produjeron en los mismos textos desde su anterior publicación en la Revista Multicolor hasta la última edición. Precisamente, la comparación con la edición de 1965 fue, en estas investigaciones, pensada como un marco para estudiar la originalidad de la primera edición (sus intenciones, la ruptura que generó), y no tanto como un espacio para pensar los motivos por los que se volvió a editar tiempo después. Entre los antecedentes de la antología y sus "alrededores", los investigadores han realizado un minucioso análisis de los discursos críticos en torno al fantástico, quedan por analizar los cambios de textos literarios que la conformaron, en el marco de sus sucesivas publicaciones.

7 De la misma manera, Donald Mc. Kenzie ha señalado que "nuevos lectores hacen $[\ldots]$ nuevos textos y [...] sus nuevos significados son consecuencia de sus nuevas formas" (46); de este modo, las distintas versiones de un mismo texto testimonian "un conjunto preciso de significaciones en sucesivos momentos de la historia" (53). 
de Crítica. Una segunda etapa, en la cual pasaron a formar parte de una antología fantástica compilada por Borges, Silvina Ocampo y Bioy Casares en la editorial Sudamericana, como primer número de la colección Laberinto. Y finalmente, un momento de recuperación de esos textos, para volver a un público más acostumbrado a este tipo de literatura como parte de una edición de bolsillo, en concordancia con la consolidación de la posición que ocupaba la casa editora en el campo editorial argentino.

Las sucesivas ediciones habrían implicado, además de cambios en la materialidad de los textos, una relectura y una corrección por parte de los antólogos, operaciones que se vincularon de manera más o menos directa con el momento y el espacio en el que fueron publicados ${ }^{8}$. Nos centraremos particularmente en la manera en que la escritura y traducción de los textos se relacionó con todo un aparato editorial compuesto por una organización en colecciones, un conjunto de componentes paratextuales (imágenes, comentarios, prólogos, referencias) (Willson), pero también teniendo en cuenta las importantes diferencias entre los dos soportes en los que aparecieron: el libro y la prensa periódica9 .

$8 \quad$ Como ha observado Bourdieu, "cada editorial ocupa en un momento dado, una posición en el campo editorial, que depende de su posición en la distribución de los recursos raros (económicos, simbólicos, técnicos, etc.) y de los poderes que ellos confieren sobre el campo [...]. El más importante de los cambios observados en la política editorial de las diferentes editoriales puede, así, estar relacionado a cambios de la posición que ellas ocupan en el campo" (Bourdieu, "Una revolución” 224-225).

9 En este sentido, es importante señalar la distinción realizada por Horacio Tarcus: "La revista tiene un tiempo de circulación más veloz que el libro y anticipa los textos que el libro se va a demorar en recoger. La revista, campo de pruebas y ensayos, avanza y arriesga, mientras el libro selecciona, recoge, decanta, consolida. En este sentido, cualquiera sea su orientación política o estética, la revista es siempre vanguardista mientras que el libro es conservador. Por eso la revista envejece rápidamente mientras que el libro sobrevive" (Tarcus 2). 


\title{
I. LA LITERATURA FANTÁSTICA EN EL SUPLEMENTO DE UN DIARIO MASIVO: UN ESPACIO PARA LO NUEVO
}

\begin{abstract}
El verdadero comienzo de mi carrera de escritor se sitúa en una serie de bosquejos titulada Historia Universal de la Infamia, pensados como colaboraciones para las columnas de Crítica [...]. Los artículos iban destinados al consumo popular a través de las páginas de Crítica y resultaban marcadamente pintorescos. Supongo ahora que el valor estético de aquellos bosquejos -además del placer sutil que me producía escribirlos- residía en el hecho de constituir ejercicios narrativos. Jorge Luis Borges (1974).
\end{abstract}

Si bien el epígrafe no hace referencia a los relatos fantásticos escritos en el suplemento de Crítica, nos permite reflexionar sobre los vínculos entre una de las principales característica de este soporte -su "consumo popular"-, las exigencias del público al que se dirigía -que parecen excusar a Borges del "pintoresquismo" de sus artículos-, y la libertad con la que contarían los escritores en la prensa para practicar sus "ejercicios narrativos" 10 . En su importante investigación sobre Crítica, Sylvia Saítta ha destacado el interés del diario por la promoción de las novedades literarias y la temprana incorporación en su redacción de varios escritores que colaboraban al mismo tiempo en el periódico vanguardista Martín Fierro (segunda etapa, 19241927) (Saítta, Regueros de tinta). El diario Crítica, que desde sus inicios se habría identificado con "lo nuevo", pocos años antes del surgimiento de su suplemento había promocionado la poética de los escritores nucleados alrededor de la principal revista de vanguardia argentina, a la vez que les había dado un lugar en su redacción ${ }^{11}$ : "La iniciativa de Botana brindó una dimensión espectacular (Crítica tenía por entonces tirajes realmente elevados) al impulso que los muchachos de Florida destinaban a los 20 o 30 mil lectores de Martín Fierro" (Rivera, El escritor 82).

10 Borges no solo participó en la $R M S$ como director, sino que también publicó en ella los relatos que un año después del cierre de este suplemento conformarían el libro Historia Universal de la Infamia (1935), estos textos aparecieron de manera esporádica en una sección que llevaba el mismo nombre.

11 Jorge Luis Borges, Norah Lange, Guillermo Juan Borges, Alejandro Schultz (Xul Solar), Pablo Rojas Paz, Ulyses Petit de Murat, los hermanos Dabove, Horacio Rega Molina, Ricardo Setaro, Raúl González Tuñón, Carlos de la Púa son algunos de los escritores nucleados en Martín Fierro que luego colaboraron en la Revista Multicolor de los Sábados. 
Desde comienzos del siglo XX, el proceso de alfabetización, la ampliación del mercado y la modernización que había empezado a desarrollarse en Argentina produjeron una ampliación del público lector. Esto generó cambios en la prensa de Buenos Aires, que "abandonó la lógica exclusivamente informativa para ofrecer a sus lectores propuestas ficcionales" (de Sagastizábal 48), entre las cuales se encontraban las colecciones de libros traducidos que lanzaron los periódicos a precios económicos, como se puede observar en la Biblioteca de La Nación y la Biblioteca Crítica ${ }^{12}$. Estas iniciativas, "desde distintas perspectivas trata[ro]n de dar respuesta a los nuevos lectores" (Rivera, El escritor 34). Una de las particularidades de este período fue, entonces, la edición de libros económicos, que ya en la década de 1920 comenzaron a ser difundidos no solo por periódicos sino también por varias empresas editoriales destinadas a una "amplia franja de público lector [...] cuyo acceso a la cultura letrada se establece a través de una serie de mediaciones traducida en una variada tipología de impresos que incluye desde folletos hasta compilaciones" (Delgado y Espósito 67).

Pese a la proliferación de libros y traducciones con fines didácticos, en la sección "Actualidades del mundo literario" de Crítica Magazine (revista tabloide que el diario de Botana ofreció a sus lectores entre 1926 y 1927), un testimonio anónimo señalaba la mala calidad de los libros argentinos por ese entonces, hecho que se explicaba por una preferencia económica de los imprenteros hacia la publicación de otro tipo de materiales impresos por sobre el libro:

Los peores enemigos del libro bien presentado son ¡oh ironía! los dueños de imprentas y talleres gráficos, impermeables a toda renovación estética. Luego, les siguen los libreros, que se niegan a presentar en las vidrieras los libros cuyas tapas no tengan otro fin que atraer colorísticamente a los viandantes.

Nuestros bibliófilos se quejan del papel, del tipo empleado y de la mala tinta, que pierde vigor hasta hacer ilegible, en algunas ocasiones, el texto, a poco tiempo de publicado. Esto ocurre porque el ramo del libro es, en nuestras imprentas, accesorio. Más les preocupa y conviene

12 Para más detalles sobre estas colecciones, cfr. Willson y Merbilhaá. Para más detalles sobre la venta de libros económicos en ese período, cfr. Luis Alberto Romero, "Una empresa cultural: los libros baratos". En: Gutiérrez, Leandro y Romero, Luis Alberto. Sectores populares, cultura y política: Buenos Aires en la entreguerra. Buenos Aires: Siglo XXI. 
imprimir revistas, volantes, carteles, folletos y publicaciones diversas (Crítica Magazine 10).

Ante las malas ediciones de libros, pocos años después, el diario de Botana implementó la mejor tecnología de impresión en su suplemento literario, el único del mercado publicado completamente en multicolor. Asimismo, a diferencia del resto de los suplementos publicados por los principales diarios de la época (La Nación y La Prensa), la RMS publicaba una mayor cantidad de textos ficcionales acompañados por grandes ilustraciones.

En el caso de la publicación de los nueve textos que elegimos para analizar en este trabajo, el orden en que fueron apareciendo en el suplemento dista del que luego tendrían en las sucesivas ediciones de la antología. El primero que se publicó fue "El brujo postergado" (2 de septiembre de 1933), sin firma, en un recuadro pequeño de la última página, con la aclaración de que el texto había sido tomado del capítulo 11 del Libro de Patronio, estaba acompañado por dos ilustraciones anónimas ${ }^{13}$. En segundo lugar se publicaron los "Relatos chinos" (14 de octubre de 1933), en la última página del suplemento, con dos ilustraciones que aludían a la cultura oriental. Luego apareció "Ser polvo", del argentino Santiago Dabove (30 de diciembre de 1933), en la página 4, acompañado por dos ilustraciones ${ }^{14}$; en cuarto lugar y en la página 2, "Donde su fuego nunca se apaga", de May Sinclair (13 de enero de 1934), que ocupaba la hoja entera y estaba acompañado por tres imágenes de tamaño mediano ${ }^{15}$. A continuación apareció "El caso del difunto Mr. Elvesham" de H. G. Wells (17 de febrero de 1934), también en la segunda página, acompañado por una

13 La primera de ellas aludía a la humildad del deán en el momento de pedir ayuda a Don Illián; en la segunda, por el contrario, dos personas besaban las manos y los pies del deán, cuyo rostro mostraba signos de soberbia.

14 En las ilustraciones se mostraban dos momentos importantes de la trama: el primero representaba el comienzo del cuento, en el que el protagonista se encontraba caído de su caballo, frente al cementerio, y el segundo mostraba cómo el personaje sufría su metamorfosis y se convertía, ante la vista azorada de alguien que intentaba ayudarlo, en una planta. Dabove ya había publicado en la $R M S$ otros dos relatos: "La muerte y su traje" (9 de septiembre de 1933) y "El espantapájaros y la melodía" (11 de septiembre de 1933).

15 La imagen central ilustraba a dos enamorados abrazados mirándose, mientras que las otras dos, ubicadas en la parte inferior de la página, mostraban sucesivamente a la protagonista corriendo y escapándose con la mirada aterrada, y a la misma tratando de apartarse de una sombra que la envolvía, en cuyo rostro nuevamente se plasmaba la expresión de susto. 
notícula que presentaba al autor y dos imágenes ${ }^{16}$. Varios meses después, se publicaron "El teólogo" y "Dos que soñaron" (ambos el 23 de junio de 1934), uno debajo del otro en la columna derecha de la segunda página del suplemento, acompañados por imágenes muy pequeñas que hacían alusión a las dos historias contadas; el segundo de ellos apareció sin autor. El próximo texto en ser publicado fue el acto único "Donde está marcada la cruz" de Eugenio O’Neill (7 de julio de 1934), que ocupó dos páginas y apareció junto con enormes ilustraciones intercaladas en el texto. El último relato, "Los ganadores de mañana", de Holloway Horn (14 de julio de 1934), salió en la página 5, junto a la sección "Museo de la confusión", de Anímula Vagula (seudónimo de Guillermo J. Borges), y de la historieta "El nuevo rico", de H. Rodríguez. Este cuento apareció ilustrado por dos imágenes ${ }^{17}$.

Como puede observarse, los nueve cuentos salieron de manera esporádica, los dos primeros en pequeños recuadros de la contratapa, varios de entre los que les siguieron aparecieron en la segunda página. La extensión de estos textos varió desde recuadros de tamaño chico hasta las dos carillas del acto único de O'Neill. Esta diversidad y yuxtaposición continuaría en la $A L F$, que reunió en sus páginas textos de distintos tipo y extensión ${ }^{18}$. En general, todos contaron con al menos dos ilustraciones: una en la que se hacía referencia al momento inicial del texto y otra en la que se mostraba al protagonista $\mathrm{u}$ otro personaje sorprendido u horrorizado.

Las ilustraciones aportaron una mayor agilidad en la lectura de estos textos fantásticos a la vez que vincularon las escenas narradas en las ficciones con un determinado tipo de relato ilustrado del diario -aquel en el que se especulaba sobre un crimen o un criminal-. En los 61 números de la $R M S$ no se encuentra una sola fotografía, sino grandes imágenes a todo color que ocuparon las páginas, en muchas ocasiones, con un tamaño mayor que los textos literarios,

16 En la primera de ellas puede verse a un anciano en camisón caído frente a su escritorio, de fondo se observa una parte de su biblioteca llena de libros; en la segunda se ve más de cerca al mismo hombre en camisón que mira asustado al lector, mientras una parte de su cuerpo intenta esconderse detrás de una cortina.

17 La primera ilustra un hipódromo lleno de gente, lugar donde acontecía la trama, la otra muestra a un hombre que ostensiblemente tiene dinero a quien otro le señala algo en su diario.

18 Es llamativo también que "La sentencia", el último relato que se incorporó en la antología de 1965, fue uno de los primeros en aparecer en la $R M S$, como parte del artículo "Relatos chinos". 
influyendo así en su lectura ${ }^{19}$. El suplemento se diferenciaba del diario en el hecho de no incluir fotografías en sus páginas. Sin embargo, los lectores de los cuentos fantásticos publicados en la $R M S$ estaban acostumbrados a ver en las notas de Crítica un tipo particular de ilustraciones que cumplían funciones específicas ligadas a aquello que la fotografía no podía mostrar, pero que, sin embargo, pretendía copiar el estilo fotográfico (por ejemplo mediante la ilustración de retratos o de cuerpos en movimientos sorprendidos por el disparo de la cámara): representaciones de crímenes, identikits, perfiles lombrosianos ${ }^{20}$. La ausencia de fotografías en la $R M S$ y su reemplazo por las ilustraciones puede vincularse con un acercamiento a un tipo de información visual que en el diario formaba parte del terreno de la especulación, de lo no comprobado. Esto se conjugó con otro elemento fundamental propio del suplemento: el color, asociado con el entretenimiento.

Se puede afirmar, entonces, que la $R M S$ fue un contexto de producción colectivo $^{21}$ en el que emergieron los cuentos fantásticos en contacto con un importante contenido paratextual, de fuerte incidencia en su lectura. En varios casos, los relatos fueron acompañados por pequeñas notas que presentaban a los autores, o insertaban los textos en una tradición ${ }^{22}$, o ponían en relación

19 Por momentos, podría pensarse que tanto la presencia de imágenes coloridas como la gran cantidad de textos ficcionales se vincularían con propósitos didácticos con el fin de orientar el suplemento hacia un público no experto; sin embargo, en la sección de reseñas de textos eruditos y de novedades literarias se observa también un discurso dirigido a un lectorado más especializado. Por otra parte, los textos literarios que ofreció la $R M S$ se alejaron de los propósitos "edificantes" o moralizadores de otros proyectos populares como los de las revistas Claridad y Los Pensadores, de Antonio Zamora.

20 De acuerdo con esto, Annick Louis ha señalado: "Le travail sur le portrait dans la revue [la $R M S$ ] montre á quel point les dessinateurs étaient conscients de l'emploi d'une technique et de l'autre. Ils sont toujours dessinés (il n'y a qu'une exception), qu'il s'agisse d'illustrer des biographies, des notes sur des realisateurs de cinéma, sur des écrivans, des notes bibliographique. L'image semble parfois imiter la photo du journal" (Louis, Jorge Luis Borges 95).

21 En este sentido, consideramos que, frente al aislamiento de la serie literaria y el estudio de la figura de autor como aspectos predominantes en los trabajos de investigación realizados hasta ahora, se hace necesario un estudio de la $R M S$ como contexto de producción colectivo de la literatura, conformado por distintas discursividades y estilos que lo acercaron y distanciaron del periódico vespertino en el que se publicó.

22 Como es el caso de los relatos chinos, que contaron con la siguiente nota introductoria en la que, entre otras cosas, se explicaban algunos aspectos fantásticos vinculados con el país de origen de estas historias: "La idiosincrasia del pueblo chino es la única en su género y no tiene nada de semejante en el mundo entero. El folklore de aquel pueblo representa una 
el cuento con otros textos del suplemento ${ }^{23}$. Ese modo de presentar a los autores también distó de las notas de presentación que se ofrecerían luego en las sucesivas ediciones de la $A L F$. En la $R M S$, las notas tuvieron un carácter más bien explicativo y orientativo, traducían los principales títulos del autor al castellano y comentaban el argumento del relato, mientras que las notas de la $A L F$ estarían orientadas a un público más experto, dado que se detenían en la (o las) ocupación (u ocupaciones) del autor y hacían referencia a sus libros publicados en el idioma original, como se observa a continuación:

\begin{tabular}{|c|c|}
\hline $\begin{array}{l}\text { "El caso del difunto Míster Elvesham" } \\
(\text { RMS 2) }\end{array}$ & $\begin{array}{l}\text { "El caso del difunto Míster Elvesham" } \\
\text { (ALF 163) }\end{array}$ \\
\hline $\begin{array}{l}\text { H. G. Wells -el famoso autor de La isla } \\
\text { del Doctor Moreau, La máquina del } \\
\text { tiempo, El hombre invisible, El país de } \\
\text { los ciegos y Los primeros hombres de la } \\
\text { luna- refiere aquí la historia terrible de } \\
\text { un hombre a quien le robaron el cuerpo. }\end{array}$ & $\begin{array}{l}\text { H. G. Wells, novelista, cuentista, } \\
\text { enciclopedista. Nació en Blomley en } 1866 . \\
\text { La literatura fantástica le debe muchos } \\
\text { ejercicios coherentes. En esta disciplina } \\
\text { sus libros más admirables son: The Time } \\
\text { Machine (1895); The island of Doctor } \\
\text { Moreau (1896); The Plattner Story and } \\
\text { Others (1897); The Invisible Man (1897); } \\
\text { Tales of Space and Time (1899); The First } \\
\text { Man in the Moon (1901); Twelve Stories } \\
\text { and a Dream (1903). }\end{array}$ \\
\hline
\end{tabular}

La mayor parte de estos nueve textos fueron traducciones (la única excepción es el cuento de Santiago Dabove, puesto que incluso "El brujo postergado" fue adaptado -de hecho, en ambas ediciones de la $A L F$ se presentó como una versión de Borges en Historia Universal de la Infamia-). Ni en el suplemento ni luego en la antología (1940 y 1965) se mencionaron los nombres de los traductores, excepto en la pieza teatral "Donde está marcada la cruz", de O’Neill, traducción que se asignó a Ulyses Petit de Murat y Borges en la

mezcla monstruosa, misteriosa y a la vez sencilla de lo fantástico con la vida cotidiana. Para el chino no existen fronteras entre el mundo real y el del más allá" (RMS 8).

23 Esto puede verse en el relato "El teólogo", acompañado de una pequeña nota en la que se recomendaba leerlo en relación con otro cuento que había aparecido en el mismo número de la $R M S$, y que tenía la misma temática: "Lo anterior (que el curioso lector puede comparar con el cuento 'El hallazgo de lo absoluto', de May Sinclair), es obra de Manuel Swedenborg, eminente ingeniero y hombre de ciencia, que durante veintisiete años estuvo en un comercio lúcido y familiar con el otro mundo" (RMS 2). 
$R M S$. En la antología el lector puede dar por supuesto que los traductores fueron los mismos compiladores; en el suplemento, en cambio, esta estrategia puede pensarse como parte de un borramiento de los rasgos extranjerizantes de los textos traducidos, a fin de hacerlos más cercanos al lector argentino y, específicamente, bonaerense.

Un claro ejemplo de este afán es la traducción de los textos a la variante rioplatense del idioma español, aspecto que desapareció luego en las dos ediciones de la antología ${ }^{24}$, tal como puede observarse en el siguiente cuadro comparativo:

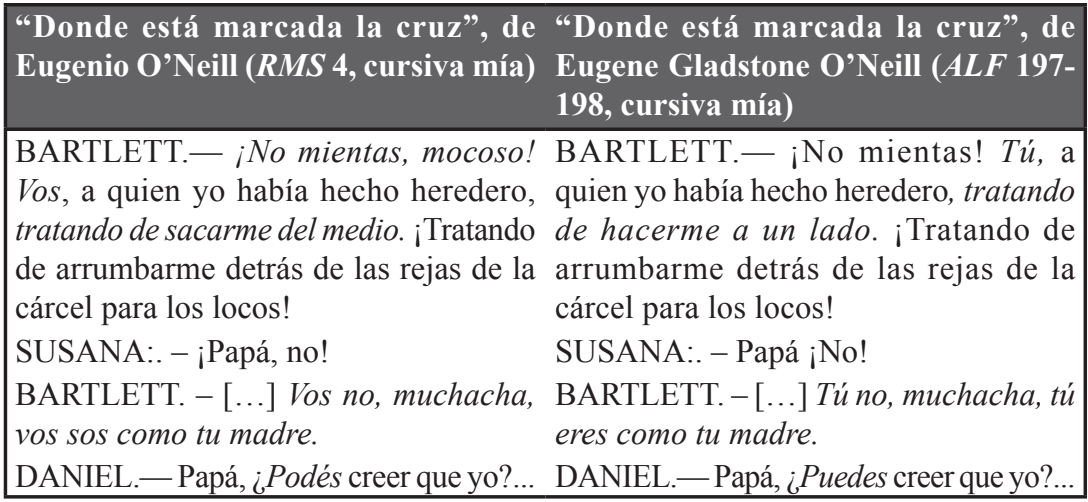

De este modo, en su publicación en el diario, estos textos presentaron una clara orientación hacia un lectorado argentino, principal -aunque no exclusivamentebonaerense y lector del diario, acostumbrado a la nota sensacionalista y a las reconstrucciones gráficas de los crímenes. Los cuentos de la antología, en cambio, se habrían dirigido a un público más amplio, lo que podría vincularse con los intereses de la editorial que la publicó (Sudamericana), orientados a la venta y distribución del libro en otros países de habla hispana. De manera que aquellos pronombres personales, aquellas formas verbales y los localismos

$24 \quad$ La traducción a la variedad rioplatense del español puede vincularse con una estrategia que Beatriz Sarlo identifica en los relatos de Historia Universal de la Infamia, de Borges (1935), cuyo primer contexto de publicación fue también la Revista Multicolor de los Sábados, y que consistiría en el trabajo sobre historias extranjeras "acriolladas por la escritura" (Sarlo 22). 
que en el suplemento acercaban las traducciones a sus lectores argentinos, luego serían reemplazados por una terminología que se pretendería más neutra.

\section{REESCRITURA Y PROMOCIÓN DE LO FANTÁSTICO EN SUDAMERICANA: DE ARGENTINA A HISPANOAMÉRICA}

Este volumen es el número 1 de la colección LABERINTO, que ofrecerá al público de habla hispánica lo perdurable y lo viviente de las diversas disciplinas de la literatura mundial. Textos sabiamente elegidos, escrupulosas versiones de las obras extranjeras, clara y elegante tipografía, definen esta biblioteca de apasionante interés y extraordinario valor cultural.

$A L F$ - Solapa (1940)

El texto de presentación de la primera edición de la $A L F$, que ocupó el espacio de su solapa interna, parece sugerir una serie de cambios importantes en cuanto al primer contexto de edición de los cuentos que conforman nuestro corpus de análisis. En principio, ellos pasaron de un suplemento a una antología. Esto hizo que, por una parte, conservaran su propiedad de textos publicados (y leídos) en un espacio colectivo. De hecho, si bien aparecieron en un orden diferente al que habían tenido en su publicación en el suplemento, en el aparente desorden de la primera $A L F$, algunos de aquellos nueve textos continuaron manteniéndose cerca unos de otros ${ }^{25}$.

Por otra parte, la publicación parecería ya no estar orientada hacia un público masivo sino a quienes estuvieran dispuestos a leer una selección "escrupulosa". Lejos de aquella queja anónima que en Crítica Magazine había denunciado la mala calidad del papel, la tinta y los tipos empleados en la edición de libros, ahora el material se ofrecía ya no en papel prensa sino en una edición cuidada, "elegante", cuyo valor ascendía a los 3,50 pesos, y que no solo estaba orientada a un lectorado rioplatense sino al de habla "hispánica". Ante aquellas páginas ahora lejanas y perdidas del suplemento,

25 "Ser polvo" de Dabove se encontraba entre "Tlon Uqbar Orbis Tertius" de Borges y "Los ganadores de mañana" de Horn; después de "Donde su fuego nunca se apaga" de Sinclair, apareció "Un teólogo en la muerte" de Swedenborg; "Historia de dos que soñaron" de Weil, antecedió a "El caso del difunto Míster Elvesham" de H.G Wells. 
la nota editorial prometía también una mayor perdurabilidad de los textos. Algunas de estas cuestiones se vincularon, por un lado, con los cambios y la expansión del mercado editorial en Argentina, que venían aconteciendo desde los últimos años de la década de 1930; y, por otro, con algunos aspectos particulares de las políticas editoriales de Sudamericana que pudieron haber incidido, como veremos, en una relectura y reescritura de las ficciones.

Los ocho textos que la antología tomó del suplemento ${ }^{26}$ coincidieron en el planteamiento de lo fantástico ligado a la ambigüedad, a un estado de vigilia en el que el protagonista no sabe si está vivo o si está muerto, si está soñando o está despierto, si lo que está viviendo forma parte de su realidad o es una alucinación. El cielo y el infierno se presentaban en ellos como lugares engañosos que se asemejaban a la tierra. Estas nuevas formas de lo fantástico se distanciaron de los usos del género que habían hecho a comienzos del siglo XX escritores argentinos como Leopoldo Lugones, Horacio Quiroga y Eduardo Ladislao Holmberg, cuyos relatos eran de carácter cientificista y positivista $^{27}$. La promoción de un nuevo tipo de fantástico en este volumen se puede ver no solo en la incorporación de nuevas traducciones sino en la omisión de ciertos autores, explicitada en el prólogo redactado por Bioy Casares: "Deliberadamente hemos omitido: a E.T.A. Hoffmann, a Sheridan Le Fanu, a Ambrose Bierce, a M. R. James, a Walter de la Mare" (Borges et al. 15).

En cuanto a la casa que editó la antología, entre los últimos años de 1930 y 1955 se desarrolló en el mercado editorial argentino un período que ha sido considerado como la "época de oro" de la edición (Rivera, El escritor; de Sagastizábal; de Diego ${ }^{28}$. De esa misma época databa la fundación de la editorial argentina Sudamericana, en el año 1939. Entre sus fundadores se encontraba Victoria Ocampo, en cuya importante revista (Sur) Borges y Bioy Casares escribieron por esos años reseñas y ensayos sobre la literatura

26 El noveno texto que conforma nuestro corpus fue incorporado en la segunda edición de la $A L F$; se trata del cuento "La sentencia", que en la $R M S$ formaba parte del artículo "Relatos Chinos".

27 Cfr. Quereilhac.

28 En ese momento surgieron las principales casas editoriales de trayectoria, aumentó la cantidad de obras registradas y el país se posicionó como un mercado exportador de libros (de Diego 97, Rivera, El escritor 95). Esta situación fue, en gran parte, ocasionada por el colapso de la industria editorial española tras la guerra civil (1936-1939), y la migración de editores de la península ibérica a nuestro país. 
fantástica ${ }^{29}$. En 1940 serían Antonio López Llausás y Julian Urgoiti quienes se encargarían de la empresa. Patricia Willson ha identificado la fundación de esta editorial como uno de los mecanismos de irradiación de las prácticas traductoras de $\operatorname{Sur}^{30}$ (Willson 230), dado que Sudamericana reeditó y distribuyó su fondo editorial. Este hecho, como ha señalado de Diego, impulsó una relación prácticamente inmediata entre ambas editoriales (de Diego 103), lo cual nos permite pensar que no sería casual la publicación de este libro compilado por tres activos miembros -si bien jóvenes- del grupo Sur. Entre los objetivos de Sudamericana, Gloria López Llovet identificó la promoción de autores latinoamericanos y, al mismo tiempo, la traducción y divulgación de literatura extranjera (Lopez Llovet 9). Si como señala Jean-Marc Gouanvic, "El editor, sometido a la libre competencia, 'busca imponer' en el campo un nuevo productor y un nuevo producto, vectores de un nuevo sistema de gustos, y capaces de originar un reacomodamiento de las jerarquías de gustos vigentes en el campo" (Gouanvic 10), el gerente de Sudamericana, al aceptar la publicación de la $A L F$ propuesta por Borges, Bioy Casares y Silvina Ocampo, colaboró en la difusión y conformación de un nuevo modo de fantástico en Argentina e Hispanoamérica.

Nuevas editoriales, difusión de nuevos autores y nuevos géneros, y también un nuevo tipo de escritura. Entre los aspectos que más llaman la atención de los textos que, después de haber sido publicados en el suplemento, ahora integraban la antología, se encuentra el cambio en algunos elementos clave de su escritura o traducción. Ni en la $R M S$ ni en las sucesivas versiones de la $A L F$ se ofreció al público lector una traducción fiel sino una versión. Esto, como hemos esbozado, sucedió incluso en el caso de textos que fueron originalmente escritos en español. El cuento "Ser polvo", del argentino Santiago Dabove, presenta en la $A L F$ de 1940 una serie de correcciones con respecto al manuscrito original publicado por primera vez en la $R M S$. De hecho, como puede observarse, la versión de 1933 coincide con la que luego se incluyó en el volumen post-mortem que reunió ese y otros cuentos del escritor (1961), en el que tan solo aparecieron leves variaciones, mientras que en el texto

29 Para un estudio más detallado de la trayectoria de Borges y Bioy Casares en Sur cfr. Gramuglio 2013.

$30 \quad$ La editorial Sur fue fundada en el año 1933 por Victoria Ocampo, quien dirigía también la revista homónima desde 1931. En el sello editorial se publicaron principalmente traducciones de autores como William Faulkner, Virginia Woolf, Samuel Beckett, Jean Genet y Graham Green, entre otros (Willson 2004). 
publicado en la antología de Borges, Bioy Casares y Ocampo, encontramos correcciones e incluso importantes ampliaciones del relato original:

\begin{tabular}{|c|c|}
\hline $\begin{array}{l}\text { "Ser polvo" ( RMS 4, } \\
\text { cursiva mía) }\end{array}$ & $\begin{array}{l}\text { "Ser polvo" (ALF 92, "Ser polvo" (Dabove, La } \\
\text { cursiva mía) }\end{array}$ \\
\hline $\begin{array}{l}\text { Como el suelo en que caí, } \\
\text { a un lado del camino, era } \\
\text { duro, y podía permanecer } \\
\text { mucho tiempo allí, y poco } \\
\text { me podía mover, me dediqué } \\
\text { a cavar pacientemente con } \\
\text { mi cortaplumas la tierra } \\
\text { alrededor de mi cuerpo. } \\
\text { La tarea resultó más bien } \\
\text { fácil porque el suelo era } \\
\text { esponjoso. Poco a poco } \\
\text { me fui enterrando en una } \\
\text { especie de fosa que resultó } \\
\text { un lecho algo más tolerable } \\
\text { que la superficie dura. } \\
\text { Me dediqué a tragar con } \\
\text { entusiasmo y regularidad } \\
\text { ejemplares, píldora tras } \\
\text { píldora de opio y eso } \\
\text { debe haber determinado } \\
\text { el "sueño" que precedió a } \\
\text { mi "muerte". }\end{array}$ & $\begin{array}{l}\text { Como el suelo en que caí, Como el suelo en que caí, } \\
\text { a un lado del camino, era a un lado del camino, era } \\
\text { duro, y podía permanecer firme, y podía permanecer } \\
\text { mucho tiempo allí, y poco mucho tiempo allí, y poco } \\
\text { me podía mover, me dediqué me podía mover, me dediqué } \\
\text { a cavar pacientemente con a cavar pacientemente con } \\
\text { mi cortaplumas la tierra mi cortaplumas la tierra } \\
\text { alrededor de mi cuerpo. La alrededor de mi cuerpo. } \\
\text { tarea resultó más bien fácil La tarea resultó más bien } \\
\text { porque, bajo la superficie fácil porque el suelo era } \\
\text { dura, la tierra era esponjosa. esponjoso. Poco a poco } \\
\text { Poco a po co me fui me fui enterrando en una } \\
\text { enterrando en una especie especie defosa que resultó } \\
\text { defosa que resultó un lecho un lecho algo más tolerable } \\
\text { tolerable y casi abrigado que la superficie dura. } \\
\text { por la caliente humedad. La Me dediqué a tragar con } \\
\text { tarde huía. Mi esperanzay entusiasmo y regularidad } \\
\text { mi caballo desaparecieron ejemplares, píldora tras } \\
\text { en el horizonte. Vino la píldora de opio y eso } \\
\text { noche oscuray cerrada. Yo debe haber determinado } \\
\text { la esperaba asi, horrorosa el "sueño" que precedió a } \\
\text { ypegajosa de negrura, con mi "muerte". } \\
\text { esperanza de mundos, de } \\
\text { luna y estrellas. En esas } \\
\text { primeras noches negras } \\
\text { pudo el espanto contra } \\
\text { mi. iLeguas de espanto, } \\
\text { desesperación, recuerdos! } \\
\text { No, no, iIdos, recuerdos!. } \\
\text { No he de llorar por mi ni } \\
\text { por... Unafinaypersistente } \\
\text { llovizna lloró por mí. Al } \\
\text { amanecer del otro día tenía } \\
\text { bien pegado mi cuerpo a } \\
\text { tragar con entusiasmo y }\end{array}$ \\
\hline
\end{tabular}




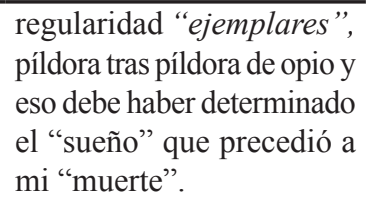

El texto de Dabove fue reescrito y completado con más detalles; en los textos traducidos, en cambio, ocurriría todo lo contrario. Pese a conservar el mismo título con el que se habían difundido en el suplemento, las traducciones de la antología presentaron una escritura menos explicativa, más compacta y sintética, depurada de la sintaxis enrevesada y del léxico menos convencional para el lector actual que aquel que tenían en la $R M S$ :

\section{"El caso del difunto Míster Elvesham" "El caso del difunto Míster Elvesham" (RMS 2, cursiva mía) ( $A L F$ 263, cursiva mía)}

Mi tío, George Eden, me adoptó como Mi tío, George Eden, me adoptó. Era único hijo. Era un hombre soltero, cuya un hombre soltero, autodidacta, y había cultura se la debía a sí mismo y gozaba de logrado cierto renombre como periodista. cierta popularidad. Costeó generosamente Costeó generosamente mis estudios y me mis estudios y siempre alentó mi ambición infundió la voluntad de progresar en el de abrirme camino en el mundo. Cuando mundo. Cuando murió, hace cuatro años, falleció, hace ya cuatro años, me hizo me dejó toda su fortuna, que ascendía a heredero de toda su fortuna que quedó unas quinientas libras, después de pagados reducida a quinientas libras después de los impuestos.

pagados los impuestos.

Si en la $R M S$ los textos traducidos se presentaban con una gran cantidad de detalles y con una terminología más compleja, en la $A L F$ (1940 y 1965) observaremos la reducción de la historia a lo esencial, como puede observarse claramente en la traducción del relato "Where Their Fire Is Not Quenched", de May Sinclair. Las traducciones de este texto que se realizaron para el suplemento y para la antología tomaron distintos elementos del relato original y agregaron otros. No obstante, en la $A L F$ puede observarse una mayor reducción del relato a lo fundamental, como se evidencia en el siguiente cuadro comparativo: 


\begin{tabular}{lll|}
\hline "Where Their Fire Is Not "Donde su fuego nunca se "Donde su fuego nunca se \\
Quenched" (Sinclair 1) & apaga" (RMS 2) & \\
& & \\
apaga" (ALF 241)
\end{tabular}


De este modo, los antólogos modificaron a su gusto los textos, mediante un trabajo de reescritura. En este sentido, quizás sea válido recordar el diálogo de Borges y Bioy Casares en torno a la traducción italiana de esta antología, en el que Borges dice:

Me hice leer algunos cuentos breves de la edición italiana de nuestra antología de la literatura fantástica. No tradujeron nuestra antología: buscaron las fuentes y tradujeron. Procedieron con seriedad a costa del lector, desde luego'. [...] 'No debieron elegir un libro de autores que se distinguen por sus transcripciones y citas infieles' (En Bioy Casares 1562, la cursiva me pertenece).

Pero además de asociarse con las ideas que particularmente Borges tenía sobre la composición del relato y sobre la traducción, estos cambios que sufrieron los textos (las reducciones de lo escrito a lo esencial, el borramiento de los localismos y de la variedad rioplatense del español), en el marco de la nueva edición en una editorial que tenía la voluntad de que sus libros llegaran a un público hispanoamericano, también podrían vincularse con una nueva política de traducción que surgió en este período, sobre todo gracias la expansión del mercado, tal como ha señalado Jorge Rivera:

[...] la situación de vacancia de la industria española [...] provocará la existencia de una suerte de 'mercado de dos cabezas', promotor de una producción destinada netamente al mercado interno y una producción de tipo más universal (naturalmente traducida) pensada tanto para el mercado local como para los mercados de España y de América Latina, engaste ciertamente complejo pero autorizado por la particular configuración cosmopolita del lector argentino, simultáneamente receptivo a productos de los más variados orígenes literarios, nacionales y culturales.

Dentro de esta tesitura "bifrontal" se organizan los catálogos de la mayoría de las grandes editoriales de la década del cuarenta, basados en cierta forma en la gran ductilidad del mercado interno, en el prestigio internacional de ciertos nombres y en la gama más amplia que permite explorar un marco potencial como el hispano-parlante (El escritor 137).

Esta ampliación fue acompañada, asimismo, por un perfeccionamiento del trabajo de traductor, que ahora sería desempeñado profesionalmente por escritores: "Frente a lo que ocurre en otras industrias [...] en el caso de la argentina prevalece desde sus inicios la figura del escritor o del especialista 
con una depurada y hasta sofisticada formación cultural y literaria" (Rivera, El escritor 100). Los cambios ocasionados en las estrategias de traducción durante este período, entonces, podrían relacionarse en varios aspectos con las modificaciones realizadas por Borges y Bioy Casares a los textos de la antología, dado que de una preferencia por la traducción de la trama en la $R M S$, se pasó a un anclaje en las normas de la lengua meta y una simplificación del texto en la $A L F$, a fin de que la colección pudiera llegar a un público no solo argentino sino hispanoamericano.

\section{CONSOLIDACIÓN DEL FANTÁSTICO Y RETORNO AL KIOSCO DE DIARIOS}

Veinticinco años después, la favorable fortuna permite una nueva edición de nuestra Antología de la literatura fantástica de 1940, enriquecida con textos de Agutagawa, de Blanco, de León Bloy, de Cortázar, de Elena Garro, de Murena, de Carlos Peralta, de Barry Perowne, de Wilcock [...]. El editor se opone a la supresión del prólogo de la edición original y me pide que escriba otro. Dejaré que me persuada, redactaré siquiera una postdata, porque en aquel prólogo hay afirmaciones de las que siempre me he arrepentido.

Adolfo Bioy Casares, "Postdata" a la ALF (1965: 15)

El lector tiene en estas páginas, no una evasión, sino cien audaces salidas al mundo de la fantasía.

Contratapa de la $A L F(1965)$

Si en la edición de 1940 la $A L F$ inauguraba la colección Laberinto de la editorial Sudamericana, en su reedición es el número 100 de la colección Piragua, que reunió a autores tan disímiles como Bertrand Russell y Victor Lindlarh, además de obras anteriormente editadas por la editorial Emecé, como Los mejores cuentos policiales compilados por Borges y Bioy Casares. La reedición, señala Bioy Casares en su postdata, es un pedido del editor. Si bien se ha observado que en la década de 1960 Sudamericana adquirió una política editorial que contribuiría a difundir masivamente la literatura argentina y latinoamericana (Aguado 2014: 141), el catálogo de obras presentes en la colección Piragua se encontraba compuesto por una importante cantidad de textos extranjeros. Sin embargo, si se tiene en cuenta los autores que se 
añadieron a este nuevo volumen sí podría considerarse una ampliación de la nómina de nombres argentinos e hispanoamericanos.

Los textos que habían sido tomados de la RMS para integrar, junto con otros, la antología de 1940 no presentaron cambios en su redacción con respecto a aquella primera edición en libro. Incluso, pese a que en el volumen de 1965 las obras se ofrecieron en un nuevo orden alfabético, la sucesión de los relatos que conforman nuestro corpus fue la misma que en 1940. Esto quiere decir que, en medio del aparente caos y yuxtaposición de la edición príncipe, los relatos que ésta había tomado de la $R M S$ establecieron en la antología un orden interno en el que se presentaban de acuerdo con una sucesión alfabética de sus autores, orden que se conservó en la nueva edición ${ }^{31}$. Podemos preguntarnos por qué en 1940 estos textos siguieron una disposición alfabética mientras el resto no, y por qué en 1965 ese tipo de orden se aplicó a todos los textos. Una posible respuesta es que esta nueva edición tuvo un carácter más bien instructivo, que su objetivo era ya no proponer sino enseñar a un conjunto de lectores ahora ampliado qué era la literatura fantástica. No se trataba de promocionar un nuevo tipo de fantástico sino que habría una pretensión de dar por sentado que esos textos eran efectivamente literatura fantástica.

Esto puede observarse no solo en el orden alfabético sino, más particularmente, en una modificación en el modo en que se presentaron los microrrelatos. Todos aquellos textos que en la edición de 1940 se presentaban al lector explícitamente como fragmentos, en la nueva edición aparecieron como textos autónomos. Ya no se trataría de pequeños relatos fantásticos que se buscaban y se extraían de dentro de otras historias sino de historias fantásticas en sí mismas. Para esto, se borraron las fuentes de los fragmentos y, al mismo tiempo, se les dio un título. Así por ejemplo, en la edición de 1940, "El brujo postergado" había sido antecedido por dos fragmentos sin título, debajo de los cuales aparecían las fuentes: "De The Man Who Knew Too Much (1922), de G. K. Chesterton" (Borges et al. 138) y "De Parmi Les Mystiques et les Magiciens du Tibet (1929), de Alexandra David Neel" (Borges et al. 138). A diferencia de los textos más largos, éstos carecían de

$31 \quad$ Más allá de presentarse intercalados entre otros relatos, al igual que en la $A L F$ de 1965, en el volumen de 1940 los textos tomados de la $R M S$ respetaron un orden de aparición alfabético: si se observa el índice, el primero de ellos es el de Santiago Dabove, páginas después aparece el de Don Juan Manuel, al que le seguirán los de O’Neill, Sinclair, Swedenborg, Weil y Wells. En la antología de 1965 se suma a este conjunto el último agregado de la $R M S$, de WuCh'eng En. 
notas introductorias sobre sus autores. En cambio, en la edición de 1965, no solo ambos textos fueron titulados (el primero recibió el título "La pagoda de Babel" y el segundo, "Glotonería mística"), sino que sendos autores fueron presentados al lector mediante breves notas, similares a las que en 1940 habían presentado a los textos más largos. Habría entonces una especie de homogeneización en la que todos los relatos, ya fueran más breves o más largos, ya fueran fragmentos tomados de otras historias o no, adquirirían el estatuto de relato fantástico autónomo.

La mayor parte de los textos que conformaron la $A L F$ de 1965 estuvieron acompañados por esas pequeñas notas de presentación, excepto varios relatos de origen oriental de cuyos autores se mencionaba solamente el nombre. En cuanto a las notas de presentación de los textos que conforman nuestro corpus, en 1965 éstas fueron revisadas y en ocasiones completadas por los antologadores con datos como profesiones y fechas de defunción de los autores y actualizaciones de los libros por ellos publicados.

La reedición de estos textos en 1965 puede considerarse parte de un proceso de consolidación de este tipo de literatura fantástica, que se distanciaba de aquella difundida durante los primeros años del siglo XX (éstas últimas asociada a ciertas tensiones entre cientificismo y misticismo que, como señalamos, había tenido a Lugones, Quiroga y Holmberg entre sus principales escritores), y que iba dirigida a un nuevo tipo de público lector. La ampliación del lectorado puede vincularse estrechamente con las particularidades de esta nueva edición. La colección Piragua de Sudamericana, que se inició en 1958, reeditó como libro de bolsillo ${ }^{32}$ alrededor de 132 títulos, entre los cuales se incluyeron las obras más importantes de la editorial, a precios bajos y en grandes tiradas de más de diez mil ejemplares (Aguado 2014: 155). La nueva edición de formato de 11 x 17 centímetros, según López Llovet, generó la venta de libros no solo en librerías sino en otros puntos de venta como los kioscos de diarios (López Llovet 45). En este sentido, dada la reimpresión de sus mejores textos, podemos coincidir con Bourdieu en que el desplazamiento de una editorial, en este caso Sudamericana, hacia "las posiciones dominantes se acompaña de un reforzamiento de la tendencia a privilegiar la gestión de los logros en detrimento de la búsqueda de la innovación” (Bourdieu, Una revolución 225).

32 Éste era un formato bastante novedoso para la época, si se tiene en cuenta que hasta ese momento, en Argentina, tan solo las editoriales Austral y Contemporánea habían popularizado un formato apenas mayor, cuasi-pocket. 
Entre 1962 y 1968, años del llamado "boom del libro argentino"33, al igual que en los años veinte y treinta, la literatura volvió a los kioscos: "Autores hasta entonces reservados al circuito de las librerías (e inclusive a cierto tipo de librerías), como Borges o Cortázar, comparten exitosamente el efímero protagonismo del kiosco con verdaderas luminarias de la literatura masiva y del gusto popular" (Rivera, El escritor 141).

Podemos decir que aquellos textos que habían sido difundidos en un medio masivo a comienzos de los años treinta ahora volvían a ser distribuidos de manera popular. Quizás ese haya sido el motivo que llevó a Borges y Bioy Casares a retomar una vez más las páginas del suplemento de Crítica que Borges había dirigido junto con Ulyses Petit de Murat, en busca de lo que se había ofrecido veinte años atrás a un lectorado ampliado.

Por otra parte, varios acontecimientos coadyuvaron a la consolidación del género en los años sesenta. En primer lugar, la publicación de otros volúmenes vinculados con la literatura fantástica y compilados también por Borges y Bioy Casares, como Cuentos breves y extraordinarios (1955); en segundo lugar, el éxito que comenzaban a tener varios autores vinculados con el grupo Sur que también practicaron el género (principalmente los mismos antologadore ${ }^{34} \mathrm{y}$ varios de aquellos cuyos cuentos se incluyeron en la nueva antología, como Julio Cortázar, Juan Rodolfo Wilcock y José Bianco). Al mismo tiempo, otro acontecimiento que influyó en la consolidación del género fue la fundación en 1955 de la editorial argentina Minotauro, especializada en ciencia ficción y literatura fantástica, cuyo director fue Francisco Porrúa, quien por la misma época era asesor de Sudamericana (desde 1958) y quien pocos años antes había pedido a Borges que prologara su primera traducción de Crónicas Marcianas de Ray Bradbury (realizada por el mismo Porrúa). Años más tarde, el afianzamiento y el auge del género se observó en la traducción

33 Señala Rivera: "la industria del libro argentina se repuso de su caída entre 1954 y 1958 y creció notablemente durante el período 1962-1968, en un proceso [...] con aspectos y motivaciones sociales, culturales y económicas muy peculiares y complejas" (Rivera, El escritor 134).

34 En el caso particular de Ocampo, Natalia Biancotto encuentra en su participación en la $A L F$ los orígenes del error de una parte de la crítica en asociar inmediatamente su literatura con el fantástico. Más que por este género, Biancotto encuentra que los relatos ocampianos están atravesados por el nonsense. En cuanto a la $A L F$, observa atinadamente que: "El cuento de Silvina Ocampo que aquí se incluye [en la $A L F$ de 1965], 'La expiación' (de Las invitadas), por cierto, tiene poco de fantástico en los términos en que tanto Bioy como Borges lo definen" (Biancotto, Del Fantástico al nonsense 41). 
de la antología de Borges, Ocampo y Bioy Casares a otras lenguas como el italiano y el inglés ${ }^{35}$.

\section{CONSIDERACIONES FINALES}

El recorrido por una serie de textos que se publicaron entre un suplemento literario y una antología nos permite reflexionar sobre el modo en que las políticas editoriales adoptadas por Crítica y por Sudamericana en distintos momentos han estado estrechamente vinculadas, por un lado, con las distintas etapas del mercado editorial argentino, y por otro, de manera más particular, con cambios no solamente en la materialidad de los textos - el soporte y formato de publicación, el paratexto que los acompañó en cada caso, la tipografía y el precio-, en los modos en que llegaron al público lector -mediante la distribución en el kiosco o en la librería-, y en las particularidades que debía tener ese público al que se pretendía llegar-argentino o extranjero, popular o selecto- sino también, y principalmente, con cambios en los modos de escritura, de traducción y de difusión de la literatura fantástica.

Como se ha observado, tanto en su publicación en el suplemento como en las distintas ediciones de Sudamericana se han modificado algunos elementos de la materialidad de los textos que fueron portadores de sentido (Chartier 1994), al mismo tiempo que algunas de las operaciones sociales que incidieron en la transferencia de los textos extranjeros al campo nacional argentino: una operación de selección de lo que se tradujo, de lo que se publicó y de quienes lo publicaron; una operación de marcación mediante la editorial, la colección, el traductor, el prologuista; y una operación de lectura (Bourdieu, Les conditions 5). El análisis de los textos deja entrever que una parte de la propuesta de renovación literaria que significó la $A L F$ ya había sido ensayada en la década del treinta en el suplemento de Crítica, un primer espacio de traducción y promoción de un tipo de relato (cuentos fantásticos y policiales) que representaría una de las zonas más renovadoras de la literatura argentina, promovida principalmente por un sector del grupo Sur y consagrada luego en soporte libro. Si entre los objetivos de una antología, de igual modo que entre los de un suplemento literario, se encuentra la promoción de nuevos autores y nuevos géneros, podemos decir que la traducción y difusión de un 
nuevo modo de literatura fantástica fue un proceso desarrollado entre Crítica y Sudamericana, entre 1933 y 1965. Entre esas tres instancias de publicación las obras no conservaron un sentido fijo y estable sino que, por el contrario, en cada caso el encuentro entre una propuesta, un momento editorial y una recepción diferentes conllevó un cambio en sus significaciones (Chartier 1994). Las reediciones han implicado una revisión tanto de la escritura de los textos como del lugar que se le otorgó al género fantástico y el modo en que este género se presentó a los lectores. Si la mayoría de estos textos fueron traducciones seleccionadas por un sector del campo literario argentino, podemos coincidir con Bourdieu en que al hacer que se publiquen los textos extranjeros de su preferencia, los agentes habrían también reforzado su posición en el campo (Bourdieu, Les conditions 4).

\section{BIBLIOGRAFÍA}

Aguado, Amelia. "1956-1975. La consolidación del mercado interno”. Editores y políticas editoriales en Argentina, 1880-2010. Dir. José Luis de Diego. Buenos Aires: FCE, 2014.

Balderston, Daniel. "De la Antología de la literatura fantástica y sus alrededores". Historia Crítica de la Literatura Argentina. Tomo 9: El oficio se afirma. Dir. Sylvia Saítta. Buenos Aires: Emecé, 2004.

Biancotto, Natalia. "Del fantástico al nonsense. Sobre la narrativa de Silvina Ocampo". Orbis Tertius. Vol XX, n²1 (2015): 39-50.

Borges, Jorge Luis et al., comp. Antología de la literatura fantástica. Buenos Aires: Sudamericana (Colección Laberinto), 1940.

comp. Antología de la literatura fantástica. Buenos Aires: Sudamericana (Colección Piragua), 1965.

Bioy Casares, Adolfo. Borges. Buenos Aires: Destino, 2001.

Bourdieu, Pierre. "Una revolución conservadora en la edición”. Intelectuales, política y poder. Buenos Aires: Eudeba (2000): 223-267.

"Les conditions sociales de circulation internationale des ideés". Actes de la recherche en sciences sociales. V. 145 (2002) : 3-8.

Chartier, Roger. El orden de los libros. Lectores, autores, bibliotecas en Europa entre los siglos XIV y XVIII. Barcelona: Gedisa, 1994.

Costa, Walter C. "Las traducciones de la Antología de la literatura fantástica de Borges, Bioy Casares y Silvina Ocampo". Cuadernos Americanos, n 129 (2009): 159-167.

de Diego, José Luis. “1938-1955. La “época de oro’ de la industria editorial”. Editores y políticas editoriales en Argentina, 1880-2010. Dir. José Luis de Diego. Buenos Aires: FCE, 2014.

de Sagastizábal, Leandro. La edición de libros en la Argentina: una empresa de cultura. Buenos Aires: Eudeba, 1995. 
Dabove, Santiago. "Ser polvo". RMS, n 21 (1933): 4.

La muerte y su traje. Buenos Aires: Calicanto, 1961.

Delgado, Verónica y Fabio Espósito . “1920-1937. La emergencia del editor moderno”. Dir. José Luis de Diego. Editores y politicas editoriales en Argentina, 1880-2010. Buenos Aires: FCE, 2014.

Gramuglio, María Teresa. “Bioy, Borges y Sur. Diálogos y duelos”. Nacionalismo y cosmopolitismo en la literatura argentina. Rosario: Editorial Municipal de Rosario, 2013.

Gennette, Gerard. Umbrales. Buenos Aires: Siglo XXI, 2001.

Gouanvic, Jean-Marc. Sociocritique de la traduction, Arras : Artois Presses Université, 1999. (Traducción de Inés Santana: Introducción).

Horn, Holloway. "Los ganadores de mañana". RMS, n 49 (1934): 5.

Lopez Llovet, Gloria. Sudamericana. Antonio López Llausás, un editor con los pies en la tierra. Buenos Aires: Dunken, 2004.

Louis, Annick. Jorge Luis Borges: oeuvre et manoeuvres, París: L'Harmattan, 1997.

"Definiendo un género la Antología de la literatura fantástica de Silvina Ocampo, Adolfo Bioy Casares y Jorge Luis Borges". Nueva Revista de Filología Hispánica, v. XLIX, n 2 (2001): 409-437.

Mc. Kenzie, Donald. Bibliografía y sociología de los textos. Madrid: Akal, 2005.

Montaldo, Graciela. "La literatura como pedagogía, el escritor como modelo". Cuadernos Hispanoamericanos, $\mathrm{n}^{\circ} 445$ (1987): 40-64.

O’ Neill, Eugenio “Donde está marcada la cruz”. $R M S, \mathrm{n}^{\circ} 48,7$ de julio, 1936. p. 4.

Soledad Quereilhac. Cuando la ciencia despertaba fantasías. Prensa, literatura y ocultismo en la Argentina de entresiglos. Buenos Aires: Siglo XXI. 2016.

Rivera, Jorge B. "Los juegos de un tímido. Borges en el suplemento de Crítica", en Crisis, $n^{\circ} 38$ (1976): 20-26.

Rivera, Jorge. El escritor y la industria cultural. Buenos Aires: Atuel, 1998.

S/F “Actualidades del mundo literario”. Crítica Magazine (1926): 10.

$\mathrm{S} / \mathrm{F}$ "El brujo postergado". $R M S, \mathrm{n}^{\circ} 4$ (1933): 8.

$\mathrm{S} / \mathrm{F}$ "Dos que soñaron". $R M S, \mathrm{n}^{\circ} 46$ (1934): 2.

$\mathrm{S} / \mathrm{F}$ "El teólogo". $R M S, \mathrm{n}^{\circ} 46$ (1934): 2.

$\mathrm{S} / \mathrm{F}$ "Relatos chinos". RMS, $\mathrm{n}^{\circ} 10$ (1933): 8.

Saítta, Sylvia. Regueros de tinta. El diario Crítica en la década de 1920, Buenos Aires: Siglo XXI, 2013.

Sarlo, Beatriz. "Una poética de la ficción”. Historia Crítica de la Literatura Argentina. Tomo 9: El oficio se afirma. Dir. Sylvia Saítta. Buenos Aires: Emecé, 2004.

Sinclair, May. "Donde su fuego nunca se apaga" $R M S, \mathrm{n}^{\circ} 23$ (1934): 2.

"Where Their Fire Is Not Quenched". Uncanny Stories, 1923, https://hastaeldiaquemevaya. files.wordpress.com/2012/03/may-sinclair.pdf [27/04/2015]

Tarcus, Horacio, Ed. Catálogo de Revistas Culturales Argentinas (1890-2006). Buenos Aires: CeDInCI, 2007. 
Wells, H. G . "El caso del difunto Míster Elvesham”. RMS, nº 8 (1934): 2.

Willson, Patricia. La constelación de Sur. Traductores y traducciones en la literatura argentina del siglo XX. Buenos Aires: Siglo XXI, 2004.

Zavala Medina, Daniel. Borges en la conformación de la Antología de la literatura fantástica. Mexico D. F.: Miguel Ángel Porrúa, 2012. 